\title{
Evaluation of pai-1 polymorphisms in central and peripheral thromboembolies
}

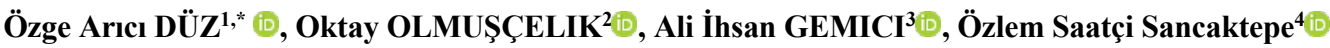

\author{
${ }^{1}$ Department of Neurology, Istanbul Medipol University, Istanbul, Turkey \\ ${ }^{2}$ Department of Internal Medicine, Istanbul Medipol University, Istanbul, Turkey \\ ${ }^{3}$ Department of Heamatology, Istanbul Medipol University, Istanbul, Turkey \\ ${ }^{4}$ Department of Ear, Nose and Throat, Training and Research Hospital, Istanbul, Turkey
}

\begin{abstract}
\begin{tabular}{ccccc}
\hline Received: 16.10 .2020 & $\bullet$ & Accepted/Published Online: 20.01 .2021 & $\bullet$ & Final Version: 14.03 .2021 \\
\hline
\end{tabular}
\section{Abstract}

Thromboembolism is a clinical finding that occurs due to thrombus; formed in the vascular system and has various etiological factors. It can be classified as central and peripheral thromboembolism. Our objective in this study is to explore genetic risk factors in central and peripheral thromboembolism and reveal the differences. 342 thromboembolism patients were retrospectively included to the study between January 2016 and December 2019. Demographic characteristics, risk factors for thromboembolism and genetic mutations in central and peripheral thromboembolism groups were overviewed. The genetic mutations evaluated in patients were Factor V Leiden G1691A, Factor V HR1299R, Factor II (Prothrombin) G20210A, MTHFR (Methylenetetrahydrofolate reductase) C677T, MTHFR A1298C, PAI 4G/5G. Within the scope of the study, genetic analyzes of 106 patients were reached and included in the study. Seventy-two central thromboembolism (69.8\%), 34 (31.2\%) peripheral thromboembolisms were detected. Sixty-three of the central thromboembolisms were from arterial and nine were from venous origin. There was no significant difference between age, gender and risk factors of central thromboembolism and peripheral thromboembolism patients $(\mathrm{p}>0.05)$, but smoking was more common in central thromboembolism patients ( $\mathrm{p}: 0.041)$. 4G/5G polymorphism was observed more frequently in patients with central thromboembolism (p: 0.039). Thromboembolism is a multifactorial disease, PAI-1 4G/5G polymorphism is a medium risk factor for thromboembolism. We conclude that PAI-1 4G/5G polymorphism is more frequent in central thromboembolism than peripheral thromboembolism and its evaluation can give more information about the thromboembolic risk analyze.
\end{abstract}

Keywords: Stroke, pai, thromboembolism, mutations

\section{Introduction}

Central and peripheral thromboembolism are common diseases with life-threatening consequences. The definition of central thromboemboli is used for thromboembolic events in the brain while thromboembolies occurring in the other organs and systems are defined as peripheral thromboemboli. Risk factors may vary, especially in young patients therefore genetic thromboembolic causes should be carefully investigated (Heit et al., 2000; Kyrle and Eichinger, 2005). Although the most frequently observed single nucleotide polymorphisms as the genetic probable risk factors are Prothrombin G2021A (PT20210A), Factor V Leiden G1691A (1), a total of 32 genes have been identified and studied (Casas et al., 2004). PAI-1 polymorphisms are also among the controversial risk factors.

Thrombus formation is regulated by the balance between two molecules found in the fibrinolytic system: the tissue type plasminogen activator (t-PA) and its inhibitor plasminogen activator inhibitor type 1 (PAI-1) (Loskutoff, 1991). The plasminogen activator inhibitor (PAI) -1 is a glycoprotein produced by the liver and endothelial cells (Liguori et al., 2014) that suppresses the formation of active plasmin which breaks down the fibrin (Pepper, 2001), thus, is associated with an increased thrombotic risk (Meltzeret al., 2010; Incalcaterra et al., 2014). High PAI-1 levels make a significant contribution to smooth muscle cell proliferation, plaque and matrix modeling and thus the formation of atherosclerosis (Roest and Banga, 2003). Thromboembolic events that may arise due to a problem in the fibrinolytic system can cause cardiovascular disease (Ploplis, 2011), cerebrovascular disease (TjarnlundWolf et al., 2012) and obstetric diseases (Su et al., 2013). In this context, PAI- 1 activity is closely related to atherosclerosis, thromboembolic events and stroke (Catto et al., 1997).

The PAI- 1 gene is located on the $7^{\text {th }}$ chromosome (Strandberg et al., 1988) and contains the nucleotide insertion/deletion polymorphism. Polymorphisms of the PAI-1 gene affect the expression of PAI-1, increasing the risk of thromboembolism (Barcellona et al., 2003). The $5 \mathrm{G}$ allele has an additional repressor protein binding site while the $4 \mathrm{G}$ allele 
does not, so the $4 \mathrm{G}$ allele produces much more mRNA in vitro than $5 \mathrm{G}$ allele and this is associated with increased PAI-1 activity in vivo (Eriksson et al., 1995). While 50\% of the population has heterozygote $(4 \mathrm{G} / 5 \mathrm{G})$ polymorphism, $25 \%$ are in $5 \mathrm{G} / 5 \mathrm{G}$ polymorphism (Liguori et al., 2014). The most common polymorphism type is $4 \mathrm{G} / 5 \mathrm{G}$ and is associated with more PAI-1 expression (Tsantes et al., 2008). 4G/4G and $4 \mathrm{G} / 5 \mathrm{G}$ polymorphisms have been reported as a risk factor for thromboembolism in many ages and ethnic groups (Kain et al., 2002; Cao et al., 2014), but there are other studies stating that there is no risk for thromboembolic diseases with these polymorphisms (Chen et al., 2003; van Goor et al., 2005). In other studies, PAI-1 levels of $4 \mathrm{G} / 4 \mathrm{G}$ carriers were found to be higher than those with $5 \mathrm{G} / 5 \mathrm{G}$ and $4 \mathrm{G} / 5 \mathrm{G}$ polymorphisms (Eriksson et al., 1995). 4G/5G polymorphism is thought to increase the risk of stroke by altering PAI-1 levels by affecting body mass index and plasma lipid levels (Dawson et al., 1993; Attia et al., 2007). Some studies reported that $4 G / 4 G$ polymorphism is neutral or protective by stabilizing the atherosclerosis plaque in terms of stroke (Endler et al., 2000).

Currently, the relationship between PAI-1 polymorphisms and thromboembolism remains a mystery. Thromboembolism can affect both arterial and venous vessels. Therefore, we aimed to reveal the differences in central and peripheral thromboembolisms in terms of PAI polymorphisms.

\section{Materials and methods}

In this study, we used hospital database from January 2016 and December 2019 to include patients retrospectively. Patients with thromboembolic diseases recorded with ICD (International Classification of Diseases, $10^{\text {th }}$ revision) and diagnosed with radiological and clinical findings were included. Demographic characteristics, age, gender, disease characteristics, hypertension, diabetes mellitus, hyperlipidemia, smoking and family history were recorded. Exclusion criteria were using anticoagulant use, having cancer, infection, autoimmune disease, renal disease or hepatic disease. 106 of 342 patients were screened for genetic thrombophilic risk factors. These patients were divided into two subgroups as central thromboembolism and peripheral thromboembolism. Central thromboembolism was defined as the arterial and venous thromboembolism belonging to the brain, while other thromboembolic events were classified as peripheral thromboembolism. The diagnosis of central thromboembolism was made according to World Health Organization (WHO) criteria and was supported by Computerized Tomography CT or Magnetic resonance imaging (MRI) (Hatano, 1976). Clinical and radiological findings were used for the diagnosis of peripheral thromboembolism. The research was performed in humans in accordance with the ethical standards of the committee responsible for human experimentation and with the Declaration of Helsinki in 1975, as revised in 2008. This study was approved by local ethics committee.
Genetic analysis was performed for thrombophilia within 1-7 days after the disease onset. The Deoxyribonucleic acid (DNA) of the patients was isolated using routine methods from peripheral blood which is taken into an Ethylene Diamine Tetra Acetic Acid (EDTA) tube. The peripheral blood sample was centrifuged for 15 minutes at $3000 \mathrm{rpm}$ and kept at $-80^{\circ} \mathrm{C}$ until the analysis. Polymerase chain reaction (PCR) method was applied by using multiplex primer pairs of variation and the presence of fluorescent stained fragments were analyzed by fragment analysis method in ABI 3500 capillary electrophoresis device. With this test, single nucleotide changes can be detected with 99\% accuracy. Genetic mutations; Factor V Leiden G1691A, Factor V HR1299R, Factor II (Prothrombin) G20210A, MTHFR C677T, MTHFR A1298C, PAI 4G/5G were analyzed. Genetic analyzes were also identified as homozygote positive, heterozygote positive and negative.

Descriptive statistics are used to define continuous variables. (Average, standard deviation, minimum, median, maximum). Non-parametric statistical methods were used for values with skewed distribution. The Kruskal-Wallis and Mann-Whitney $U$ tests were used to analyze the variables between the groups. The $\chi^{2}$ test or Fisher Exact test was used for categorical variables and expressed as observation counts and percentages. Statistical significance was accepted when $p$ value was lower than 0.05 . Statistical analysis was performed using the MedCalc Statistical Software version 12.7.7 (MedCalc Software, Belgium; http://www.medcalc.org; 2013).

\section{Results}

The mean age of the included patients was 39.6 (17-71). Seventy-two central thromboembolism (69.8\%), 34 (31.2\%) peripheral thromboembolisms were detected. Sixty-three of the central thromboembolisms were from arterial system and nine were from venous system. Eighteen patients in the peripheral thromboembolism group had a diagnosis of pulmonary embolism, 19 were diagnosed in deep vein thrombosis and 4 of them had both pulmonary embolism and deep vein thrombosis (DVT). Smoking was statistically significantly more common in patients with central thromboembolism $(\mathrm{p}=0.041$ and $\mathrm{p}$ : 0.039). The other risk factors for central and peripheral thromboembolism were not different (Table 1). $26.61 \%$ of the patients with central thromboembolism had 4G/4G polymorphism, $65.27 \%$ of them had $4 \mathrm{G} / 5 \mathrm{G}$ polymorphism and $11.6 \%$ of them had $5 \mathrm{G} / 5 \mathrm{G}$ polymorphism.

For patients with peripheral thromboembolism; $23.5 \%$ of the patients had $4 \mathrm{G} / 4 \mathrm{G}$ polymorphism, $47.1 \%$ of them had $4 \mathrm{G} / 5 \mathrm{G}$ polymorphism and $29.4 \%$ of them had $5 \mathrm{G} / 5 \mathrm{G}$ polymorphism. $4 \mathrm{G} / 5 \mathrm{G}$ polymorphism was statistically common in patients with central thromboembolism while $5 \mathrm{G} / 5 \mathrm{G}$ polymorphism was more commonly seen in patients with peripheral thromboembolisms compared to central thromboembolism (p, 0.039, 0.025, respectively) (Table 2). PAI 4G/4G polymorphism was accompanied by the Factor 
VHR1299R mutation (33.3\%) and by Factor II mutation (85.2\%) and Factor VHR1299R (33.3\%). The most common association with other genetic thrombophilia mutations was in the PAI 4G/5G polymorphism. (Table 3). Heterozygote Factor $\mathrm{V}$ Leiden mutation was more common in peripheral thrombosis ( $p, 0.009$ ), but there was no significant difference between other mutations (Table 4).

Table 1. Demographic and clinical features

\begin{tabular}{|c|c|c|c|}
\hline & $\begin{array}{c}\text { Central } \\
\text { Thromboembolism }\end{array}$ & $\begin{array}{c}\text { Peripheral } \\
\text { Thromboembolism }\end{array}$ & $\mathbf{p}$ \\
\hline Age & $40.5 \pm 10.8$ & $37.1 \pm 14.04$ & 0.183 \\
\hline Gender & $\begin{array}{c}\text { Male:37 }(49.3 \%) \\
\text { Female:35 }(50.7 \%)\end{array}$ & $\begin{array}{c}\text { Male : } 17(50 \%) \\
\text { Female : } 17(50 \%)\end{array}$ & 0.945 \\
\hline $\begin{array}{l}\text { Smoking } \\
\text { Family history }\end{array}$ & $\begin{array}{c}\mathrm{n}=15(21.7 \%) \\
\mathrm{n}=14(20.3 \%) \mathrm{var}\end{array}$ & $\begin{array}{c}n=2(11.8 \%) \\
n=8(21.4 \%) y a r\end{array}$ & $\begin{array}{c}0.041 \\
0.76\end{array}$ \\
\hline Hypertension & $\mathrm{n}=7,10.1 \%$ & $\mathrm{n}=2,5.9 \%$ & 0.471 \\
\hline $\begin{array}{l}\text { Diabetes } \\
\text { Mellitus }\end{array}$ & $\mathrm{n}=3,4.3 \%$ & $\mathrm{n}=2,5.9 \%$ & 0.733 \\
\hline Hyperlipidemia & $\mathrm{n}=5,7.2 \%$ & $\mathrm{n}=0$ & 0.108 \\
\hline $\begin{array}{l}\text { Stroke } \\
\text { Arteriel } \\
\text { Venous }\end{array}$ & $\begin{array}{c}\mathrm{n}=63,(87.5 \%) \\
\mathrm{n}=9,(12.5 \%)\end{array}$ & $\begin{array}{l}- \\
-\end{array}$ & \\
\hline $\begin{array}{l}\text { Deep venous } \\
\text { thrombosis }\end{array}$ & - & $\mathrm{n}=19,55.9 \%$ & \\
\hline $\begin{array}{l}\text { Pulmonary } \\
\text { embolism }\end{array}$ & - & $\mathrm{n}=18,52.9 \%$ & \\
\hline
\end{tabular}

\section{Discussion}

Thromboembolism has so many risk factors and genetic mutations are some of the most important of these risk factors. PAI-1 polymorphisms are defined as a risk factor which changes the balance of fibrinolytic system in the direction of thrombus formation by the effects of increased PAI-1 levels especially in $4 \mathrm{G} / 5 \mathrm{G}$ polymorphism in arterial system (Vergouwen et al., 2004; Verschuur et al., 2005). But still; the relationship between thromboembolism and PAI-1 polymorphisms is controversial (Segui et al., 2000).

$4 \mathrm{G} / 5 \mathrm{G}$ polymorphism in the PAI-1 gene is a risk factor for cardiovascular events, ischemic stroke, and venous thromboembolism (Eriksson et al.,1995; Tsantes et al., 2008), and the presence of the $4 \mathrm{G}$ allele has also been associated with venous thromboembolism (Tsantes, 2007; Tsantes et al., 2008).

Controversially in some studies, no relation was found between $4 \mathrm{G} / 5 \mathrm{G}$ polymorphism and venous thromboembolism (Gurgey et al., 2003). Although the studies focused on the differences of PAI-1 polymorphisms in the arterial and venous system, conflicting results have been reported due to differences in study methods. Aim in this study is to examine PAI polymorphisms in patients with peripheral and central thromboembolism in the same study.

Table 2. PAI gene polymorphism in central and peripheral thrombosis

\begin{tabular}{|cccc|} 
P. morphism & $\begin{array}{c}\text { Central } \\
\text { thromboembolism } \\
(\mathbf{n}=\mathbf{7 2})\end{array}$ & $\begin{array}{c}\text { Peripheral } \\
\text { thromboembolism }\end{array}$ & $\mathbf{P}(\boldsymbol{\chi} \mathbf{2})$ \\
\hline $4 \mathrm{G} / 4 \mathrm{G}$ & $17(23.61 \%)$ & $8(23.5 \%)$ & 0.706 \\
$4 \mathrm{G} / 5 \mathrm{G}$ & $47(65.27 \%)$ & $16(47.1 \%)$ & $0.039^{*}$ \\
$5 \mathrm{G} / 5 \mathrm{G}$ & $8(11.6 \%)$ & $10(29.4 \%)$ & $0.025^{*}$
\end{tabular}

Table 3. Association of PAI morphisms with other genetic thrombophilic mutations

\begin{tabular}{|cccc|}
\hline & PAI 4G/4G & PAI & PAI \\
\hline $\begin{array}{c}\text { F V Leiden } \\
\text { G1691A }\end{array}$ & $5(20.8 \%)$ & 13 & $\mathbf{5 G / 5 G}$ \\
\hline F V HR1299R & $3(33.3 \%)$ & $3(33.2 \%)$ & $6(25 \%)$ \\
& & & 3 \\
Factor II G20210A & 0 & $6(85.7 \%)$ & $(33.3 \%)$ \\
MTHFRC677T & $15(27.8(\%)$ & 28 & 1 \\
& & $(51.9 \%)$ & $(20.4 \%)$ \\
MTHFRA1298C & $11(22.4 \%)$ & 27 & 11 \\
& & $(55.1 \%)$ & $(22.4 \%)$ \\
\hline
\end{tabular}

In this study, PAI-1 polymorphisms were evaluated and PAI-1 4G/5G polymorphism was observed more frequently in patients with central thromboembolism than in patients with peripheral thromboembolism. Studies focused on PAI-1 polymorphisms and stroke showed that $4 \mathrm{G} / 4 \mathrm{G}$ polymorphism has an increased stroke risk (Tsantes et al., 2008), but also, it's reported that PAI-1 polymorphisms were not a risk factor for ischemic stroke (Catto et al., 1997; Endler et al., 2000; Roest et al., 2000). There are several studies claiming that PAI-1 levels are neurotoxic and neuroprotective by expressing excessive PAI-1 in astrocytes (Benchenane et al., 2004).

Also, inhibiting the formation of the matrix in the atherosclerotic plaque is another pathogenetic mechanism for neural protection (Roest et al., 2000). However, PAI-1 levels are positively associated with LDL, VLDL and triglyceride levels and negatively with HDL (Juhan-Vague et al., 1996). $4 \mathrm{G} / 4 \mathrm{G}$ polymorphism is also associated with high cholesterol levels (Boncoraglio et al., 2006).

In terms of other risk factors for stroke and PAI-1 comorbidity it's shown that high PAI-1 levels have also been associated with insulin resistance and obesity (Bastard et al., 2000; Sartori et al., 2001). Therefore, PAI-1 polymorphisms are associated with an increased risk of thromboembolism by its effect on risk factors of stroke and atherosclerosis. However, in our study, 4G/5G polymorphism was seen more frequently in central thromboembolism compared to peripheral thromboembolism, suggesting that the risk was also high in heterozygous polymorphisms like $4 \mathrm{G} / 5 \mathrm{G}$. This may be a result of multifactorial properties of PAI-1 and also multiple risk factors of stroke. But the risk factors are not different between peripheral and central thromboemboli patients except smoking and its $\mathrm{p}$ value is very limited.

In addition, 63 of the patients with central thromboembolism had arterial thromboembolism while only 9 of them had venous thromboembolism. Similarly, in the literature, $\mathrm{PAI}-14 \mathrm{G} / 5 \mathrm{G}$ polymorphism is reported to be a more prominent risk factor for arterial stroke (van Goor et al., 2005) but has also been reported as a risk for venous system-induced thromboembolism (Kupeli et al., 2011). In our study, PAI-1 $4 \mathrm{G} / 5 \mathrm{G}$ polymorphism was observed more frequently in the central thromboembolism originating from both the venous system and the arterial system, mostly from arterial origin, as 
compared with the literature but it didn't reach statistical significance.

Table 4. Features of other genetic thromboembolic mutations in central and peripheral thromboembolism

\begin{tabular}{|c|c|c|c|}
\hline & $\begin{array}{c}\text { Central } \\
\text { thromboembolism } \\
\text { n (\%) }\end{array}$ & $\begin{array}{c}\text { Peripheral } \\
\text { thromboembolism } \\
\text { n (\%) }\end{array}$ & $\mathbf{p}$ \\
\hline \multicolumn{4}{|l|}{$\begin{array}{l}\text { F V Leiden } \\
\text { G1691A }\end{array}$} \\
\hline Heterozygous & $10(14.5 \%)$ & $14(41.2 \%)$ & \multirow[t]{3}{*}{0.009} \\
\hline Normal & $58(84.1 \%)$ & $20(58.8 \%)$ & \\
\hline $\begin{array}{c}\text { Homozygous } \\
\text { F V HR1299R }\end{array}$ & $1(1.4 \%)$ & 0 & \\
\hline Heterozygous & $5(7.2 \%)$ & $4(11.8 \%)$ & \multirow[t]{3}{*}{0.203} \\
\hline Normal & $35(50.7 \%)$ & $11(32.4 \%)$ & \\
\hline $\begin{array}{l}\text { Homozygous } \\
\text { Factor II } \\
\text { G20210A }\end{array}$ & $29(42 \%)$ & $19(55.9 \%)$ & \\
\hline Heterozygous & $5(7.2 \%)$ & $2(5.9 \%)$ & \multirow[t]{2}{*}{0.796} \\
\hline Normal & $64(92.8 \%)$ & $32(94.1 \%)$ & \\
\hline MTHFRC677T & & & \\
\hline Heterozygous & $33(7.8 \%)$ & $21(61.8 \%)$ & \multirow[t]{3}{*}{0.17} \\
\hline Normal & $31(44.9 \%)$ & $13(38.2 \%)$ & \\
\hline Homozygous & $5(7.2 \%)$ & 0 & \\
\hline MTHFRA1298C & & & \\
\hline Heterozygous & $28(29 \%)$ & $21(61.8 \%)$ & \multirow[t]{3}{*}{0.116} \\
\hline Normal & $39(56.5 \%)$ & $11(32.4 \%)$ & \\
\hline Homozygous & $9(13 \%)$ & $2(5.9 \%)$ & \\
\hline
\end{tabular}

It has been reported that the presence of $4 \mathrm{G}$ allele in patients with genetic thrombophilia is a risk, but in patients without known risk factors, there is a lower risk factor of 4G/5G (Tsantes et al., 2008). However, the only risk factor different for groups was smoking and more common in central thromboembolism. Nicotine is known to significantly increase PAI-1 expression and plasma PAI-1 levels, especially in endothelial cells (Zidovetzki et al., 1999). Thus, both smoking and $4 \mathrm{G} / 5 \mathrm{G}$ polymorphism together that are frequently observed in central thromboembolism can increase the risk of thromboembolism especially in central thromboembolism.

Among all PAI-1 polymorphisms, the most common polymorphism accompanied by other thrombophilia mutations was the $4 \mathrm{G} / 5 \mathrm{G}$ polymorphism. The most prevelant thrombophilic mutations that were identified with $4 \mathrm{G} / 5 \mathrm{G}$ polymorphisms were Factor II, MTHFR A1298C, Factor V Leiden, MTHFR C677T polymorphisms. However, due to the low number of Factor II polymorphisms, it was assumed that it could not be evaluated clearly and comorbidity of MTHFR polymorphisms was more frequent. In previous studies, it was reported that thromboembolic risk increased in association with other mutations (Tsantes et al., 2008). When PAI-1 polymorphisms were excluded, the only difference between central and peripheral thromboembolisms among other thrombophilia genetic polymorphisms was observed in Factor $\mathrm{V}$ Leiden mutation and on our observations, we found it often as heterozygote in peripheral thromboembolism.

The most important limitation of this study is the study design as being retrospective. A prospective study which will be conducted with larger series will be precious. More homogeneous group definition will be crucial for prospective design which is another limitation of our study. The healthy control group can increase the impact of the study design.

To conclude; PAI-1 is a complex molecule that has different effects on various tissues and organs. 4G / 5G polymorphism can be a risk factor for central thromboembolism but it's not different for arterial or venous thromboembolies. Additionally, smoking and genetic thrombophilic factors can potentiate thromboembolic risk of PAI-1 polymorphisms. So, it's important to evaluate PAI polymorphisms predominantly in central thromboembolisms to determine the risk factors more accurately

\section{References}

1. Adams, H.P. Jr, Bendixen, B.H., Kappelle, L.J., Biller, J., Love, B.B., Gordon, D.L., Marsh, E.E. 1993. Classification of subtype of acute ischemic stroke. Definitions for use in a multicenter clinical trial. TOAST. Trial of Org 10172 in Acute Stroke Treatment. Stroke. 24(1), 35-41.

2. Attia, J., Thakkinstian, A., Wang, Y., Lincz, L., Parsons, M., Sturm, J., McGettigan, P., Scott, R., Meldrum, C., Levi, C. 2007. The PAI-1 4G/5G gene polymorphism and ischemic stroke: an association study and meta-analysis. J. Stroke Cerebrovasc. Dis. 16(4),173-179.

3. Barcellona, D., Fenu, L., Cauli, C., Pisu, G., Marongiu, F. 2003. Allele $4 \mathrm{G}$ of gene PAI-1 associated with prothrombin mutation G20210A increases the risk for venous thrombosis. Thromb. Haemost. 90(6),1061-4.

4. Bastard, J.P., Piéroni, L., Hainque, B. 2000. Relationship between plasma plasminogen activator inhibitor 1 and insulin resistance. Diabetes Metab. Res. Rev. 16(3),192-201.

5. Benchenane, K., López-Atalaya, J.P., Fernández-Monreal, M., Touzani, O, Vivien, D. 2004. Equivocal roles of tissue-type plasminogen activator in stroke-induced injury. Trends. Neurosci. 27 (3), 155-160.

6. Boncoraglio, G.B., Bodini, A., Brambilla, C., Carriero, M.R., Ciusani, E., Parati, E.A. 2006. An effect of the PAI-1 4G/5G polymorphism on cholesterol levels may explain conflicting associations with myocardial infarction and stroke. Cerebrovasc. Dis. 22(2-3),191-195.

7. Cao, Y., Chen, W., Qian, Y., Zeng, Y., Liu, W. 2014. Plasminogen activator inhibitor-1 $4 \mathrm{G} / 5 \mathrm{G}$ polymorphism and ischemic stroke risk: A meta-analysis in Chinese population. Int. J. Neurosci. 124(12):874-81.

8. Casas, J.P., Hingorani, A.D., Bautista, L.E., Sharma, P. 2004. Meta-analysis of genetic studies in ischemic stroke: Thirty-two genes involving approximately 18,000 cases and 58,000 controls. Arch. Neurol. 61(11),1652-1661.

9. Catto, A.J., Carter, A.M., Stickland, M., Bamford, J.M., Davies, J.A., Grant, P.J. 1997. Plasminogen activator inhibitor-1 (PAI-1) $4 \mathrm{G} / 5 \mathrm{G}$ promoter polymorphism and levels in subjects with cerebrovascular disease. Thromb. Haemost. 77(4), 730-734.

10. Chen, C.H., Eng, H.L, Chang, C.J., Tsai, T.T., Lai, M.L., Chen, H.Y., Liu, C.J., Lin, T.M. 2003. 4G/5G promoter polymorphism of plasminogen activator inhibitor-1, lipid profiles, and ischemic stroke. J. Lab. Clin. Med. 142 (2), 100-105.

11. Dawson, S.J., Wiman, B., Hamsten, A., Green, F., Humphries, S., Henney, A.M. 1993. The two allele sequences of a common polymorphism in the promoter of the plasminogen activator inhibitor-1 (PAI-1) gene respond differently to interleukin-1 in HepG2 cells. J. Biol. Chem. 268(15),10739-10745.

12. Endler, G., Lalouschek, W., Exner, M., Mitterbauer, G., Häring, 
D., Mannhalter, C., 2000. The $4 \mathrm{G} / 4 \mathrm{G}$ genotype at nucleotide position -675 in the promotor region of the plasminogen activator inhibitor 1 (PAI-1) gene is less frequent in young patients with minor stroke than in controls. Br. J. Haematol. 110(2), 469-471.

13. Eriksson, P., Kallin, B., van 't Hooft, F.M., Båvenholm,P., Hamsten, A. 1995. Allele-specific increase in basal transcription of the plasminogen-activator inhibitor 1 gene is associated with myocardial infarction. Proc. Natl. Acad. Sci. USA. 92(6), 18511855.

14. Gurgey, A., Balta, G., Boyvat, A. 2003. Factor V Leiden mutation and PAI-1 gene 4G/5G genotype in thrombotic patients with Behcet's disease. Blood Coagul. Fibrinolysis. 14(2), 121-124.

15. Hatano, S. 1976. Experience from a multicentre stroke register: a preliminary report. Bull. World Health Organ. 54(5), 541-553.

16. Heit, J.A., Silverstein, M.D., Mohr, D.N., Petterson, T.M., O'Fallon, W.M., Melton, L.J. 2000. Risk factors for deep vein thrombosis and pulmonary embolism: a population-based casecontrol study. Arch. Intern. Med. 160 (6), 809-815.

17. Incalcaterra E, Meli F, Muratori I, Corrado E, Amato C, Canino B, Ferrara F. 2014. Residual vein thrombosis and onset of postthrombotic syndrome: influence of the $4 \mathrm{G} / 5 \mathrm{G}$ polymorphism of plasminogen activator inhibitor-1 gene. Thromb. Res. 133(3), 371-374.

18. Juhan-Vague, I., Pyke, S.D., Alessi, M.C., Jespersen, J., Haverkate, F. Thompson, S.G., 1996. Fibrinolytic factors and the risk of myocardial infarction or sudden death in patients with angina pectoris. ECAT Study Group. European Concerted Action on Thrombosis and Disabilities. Circulation. 94 (9), 2057-2063.

19. Kain, K., Young, J., Bamford, J., Bavington, J., Grant, P.J., Catto, A.J. 2002. Determinants of plasminogen activator inhibitor-1 in South Asians with ischaemic stroke. Cerebrovasc. Dis. 14 (2), 7783.

20. Kupeli, E., Verdi, H., Simsek, A., Atac, F.B., Eyuboglu, F.O. 2011. Genetic mutations in Turkish population with pulmonary embolism and deep venous thrombosis. Clin. Appl. Thromb. Hemost. 17 (6), 87-94.

21. Kyrle, P.A., Eichinger, S. 2005. Deep vein thrombosis. Lancet. 365 (9465), 1163-1174.

22. Liguori, R., Quaranta, S., Di Fiore, R., Elce, A., Castaldo, G., Amato, F. 2014. A novel polymorphism in the PAI-1 gene promoter enhances gene expression. A novel pro-thrombotic risk factor? Thromb. Res. 134 (6), 1229-1233.

23. Loskutoff, D.J. 1991. Regulation of PAI-1 gene expression. Fibrinolysis. 5, 197-206.

24. Meltzer, M.E., Lisman, T., de Groot, P.G., Meijers, J.C., le Cessie, S., Doggen, C.J., Rosendaal, F.R. 2010. Venous thrombosis risk associated with plasma hypofibrinolysis is explained by elevated plasma levels of TAFI and PAI-1. Blood. 116 (1), 113-121.

25. Pepper, M.S. 2001. Role of the matrix metalloproteinase and plasminogen activator-plasmin systems in angiogenesis. Arterioscler. Thromb. Vasc. Biol. 21 (7),1104-1107.

26. Ploplis VA., 2011. Effects of altered plasminogen activator inhibitor-1 expression on cardiovascular disease. Curr. Drug. Targets. 12 (12), 1782-1789.

27. Roest, M, van der Schouw, Y.T., Banga, J.D. Tempelman, M.J., de Groot, P.G., Sixma, J.J., Grobbee, D.E. 2000. Plasminogen activator inhibitor $4 \mathrm{G}$ polymorphism is associated with decreased risk of cerebrovascular mortality in older women. Circulation. 101 (1), 67-70.

28. Roest, M., Banga, J.D. 2003. Editorial comment- genetic make-up for increased PAI-1 expression protects against stroke. Stroke. 34 (12), 2828-2829.

29. Sartori, M.T., Vettor, R., De Pergola, G., De Mitrio, V., Saggiorato, G., Della, Mea, P., Patrassi, G.M., Lombardi, A.M., Fabris, R., Girolami, A. 2001. Role of the $4 \mathrm{G} / 5 \mathrm{G}$ polymorphism of PaI-1 gene promoter on PaI-1 levels in obese patients: influence of fat distribution and insulin-resistance. Thromb. Haemost. 86 (5), 1161-1169.

30. Seguí, R., Estellés, A., Mira, Y., España, F., Villa, P, Falcó, C., Vayá, A., Grancha, S., Ferrando, F., Aznar, J. 2000. PAI-1 promoter $4 \mathrm{G} / 5 \mathrm{G}$ genotype as an additional risk factor for venous thrombosis in subjects with genetic thrombophilic defects. Br. J. Haematol. 111 (1), 122-128.

31. Strandberg, L, Lawrence, D., T, Ny. 1988. The organization of the human-plasminogen-activator-inhibitor-1 gene. Implications on the evolution of the serine-protease inhibitor family. Eur. J. Biochem. 176 (3), 609-616.

32. Su MT, Lin SH, Chen YC, Kuo PL. 2013. Genetic association studies of ACE and PAI-1 genes in women with recurrent pregnancy loss: a systematic review and meta-analysis. Thromb. Haemost. 109 (1), 8-15.

33. Tjärnlund-Wolf, A., Brogren, H., Lo, E.H., Wang, X. 2012. Plasminogen activator inhibitor- 1 and thrombotic cerebrovascular diseases. Stroke. 43 (10), 2833-2839.

34. Tsantes AE, Nikolopoulos GK, Bagos PG, Rapti E, Mantzios G, Kapsimali V, Travlou A., 2007. Association between the plasminogen activator inhibitor-1 4G/5G polymorphism and venous thrombosis. A meta-analysis. Thromb. Haemost. 97(6), 907-913.

35. Tsantes, A.E., Nikolopoulos, G.K., Bagos, P.G., Bonovas, S., Kopterides, P., Vaiopoulos, G., 2008. The effect of the plasminogen activator inhibitor- $14 \mathrm{G} / 5 \mathrm{G}$ polymorphism on the thrombotic risk. Thromb. Res. 122(6), 736-742.

36. van Goor, M.L., Gómez García, E., Leebeek F, Brouwers, G.J., Koudstaal, P., Dippel, D., 2005. The plasminogen activator inhibitor (PAI-1) 4G/5G promoter polymorphism and PAI-1 levels in ischemic stroke. A case-control study. Thromb. Haemost. 93(1), 92-96.

37. Vergouwen, M.D., Frijns, C.J., Roos, Y.B., Rinkel, G.J., Baas, F., Vermeulen, M., 2004. Plasminogen activator inhibitor-1 4G allele in the $4 \mathrm{G} / 5 \mathrm{G}$ promoter polymorphism increases the occurrence of cerebral ischemia after aneurysmal subarachnoid hemorrhage. Stroke. 35(6), 1280-1283.

38. Verschuur, M., Jellema, A., Bladbjerg, E.M., M, Feskens, E.J., Mensink, R.P., Møller, L., Vos, H.L., de Maat, M.P. 2005. The plasminogen activator inhibitor-1 (PAI-1) promoter haplotype is related to PAI-1 plasma concentrations in lean individuals. Atherosclerosis. 181 (2), 275-284.

39. Zidovetzki, R., Chen, P., Fisher, M., Hofman, F.M., Faraci, F.M. 1999. Nicotine increases plasminogen activator inhibitor-1 production by human brain endothelial cells via protein kinase $\mathrm{C}$ associated pathway. Stroke. 30 (3), 651-655. 